\title{
Rutoside and Ascorbic Acid in the Treatment of Schamberg Pigmented Purpuric Dermatosis
}

\author{
Alexandra J. Morquette ${ }^{1}$, Jason B. Lee ${ }^{2}$, Shoshana K. Grossman ${ }^{1}$, Sylvia Hsu ${ }^{1}$ \\ 1. Dermatology, Temple University Lewis Katz School of Medicine, Philadelphia, USA 2. Dermatology and Cutaneous \\ Biology, Thomas Jefferson University, Philadelphia, USA
}

Corresponding author: Jason B. Lee, jason.lee@jefferson.edu

\begin{abstract}
Schamberg disease is a type of pigmented purpuric dermatosis (PPD), which is a benign cutaneous capillaritis characterized by macules and patches most commonly found on the lower extremities. Rutoside and ascorbic acid have been shown in previous cases to be efficacious in the treatment of PPD lesions due to their free radical scavenging effect on capillaries. We present the case of a 19-year-old woman with Schamberg disease who achieved complete clearance of lesions within four months of daily rutoside and ascorbic acid treatment. The goal of this case report is to further demonstrate the effectiveness of this treatment and to call for investigation of its use as a standard of care in PPD.
\end{abstract}

Review began 02/16/2021 Review ended 04/18/2021 Published 04/20/2021

(c) Copyright 2021

Morquette et al. This is an open access article distributed under the terms of the Creative Commons Attribution License CC-BY 4.0., which permits unrestricted use, distribution, and reproduction in any medium, provided the original author and source are credited.
Categories: Dermatology

Keywords: rutoside, ascorbic acid, flavonoid, vitamin c, schamberg disease, pigmented purpuric dermatosis

\section{Introduction}

Schamberg disease, the most common type of pigmented purpuric dermatosis (PPD), is a capillaritis characterized by reddish-brown macules and patches, most commonly distributed on the lower legs, but may appear on other parts of the body [1-3]. PPD usually is not associated with any symptoms, but pruritus may occur with some lesions. Although not completely understood, theorized etiologies of PPD include drug or food additive reaction, viral infection, or exercise. Lesions can wax and wane, persist with time, or resolve over months to years. The current standard of care for PPD includes topical steroids for those with pruritus, avoiding or discontinuing triggers, and the use of compression stockings. Recent studies have shown that the use of rutoside and ascorbic acid has been effective in the treatment of PPD [4,5]. In this case report, we present a patient with PPD who experienced marked improvement with oral rutoside and ascorbic acid therapy.

\section{Case Presentation}

A 19-year-old woman presented with a two-week history of a progressive, asymptomatic rash on the bilateral legs, arms, and abdomen. Physical examination consisted of non-blanching erythematous and brown papules and macules that were most apparent on the lower extremities (Figure 1). As leukocytoclastic vasculitis was in the clinical differential diagnosis, two punch biopsies were performed for histopathology and direct immunofluorescence. The patient was initiated on a prednisone taper. Direct

immunofluorescence was negative for IgG, IgA, IgM, and C3. Histopathology evaluation revealed superficial perivascular infiltration of lymphocytes with extravasated erythrocytes, consistent with Schamberg disease (Figure 2). 


\section{Cureus}

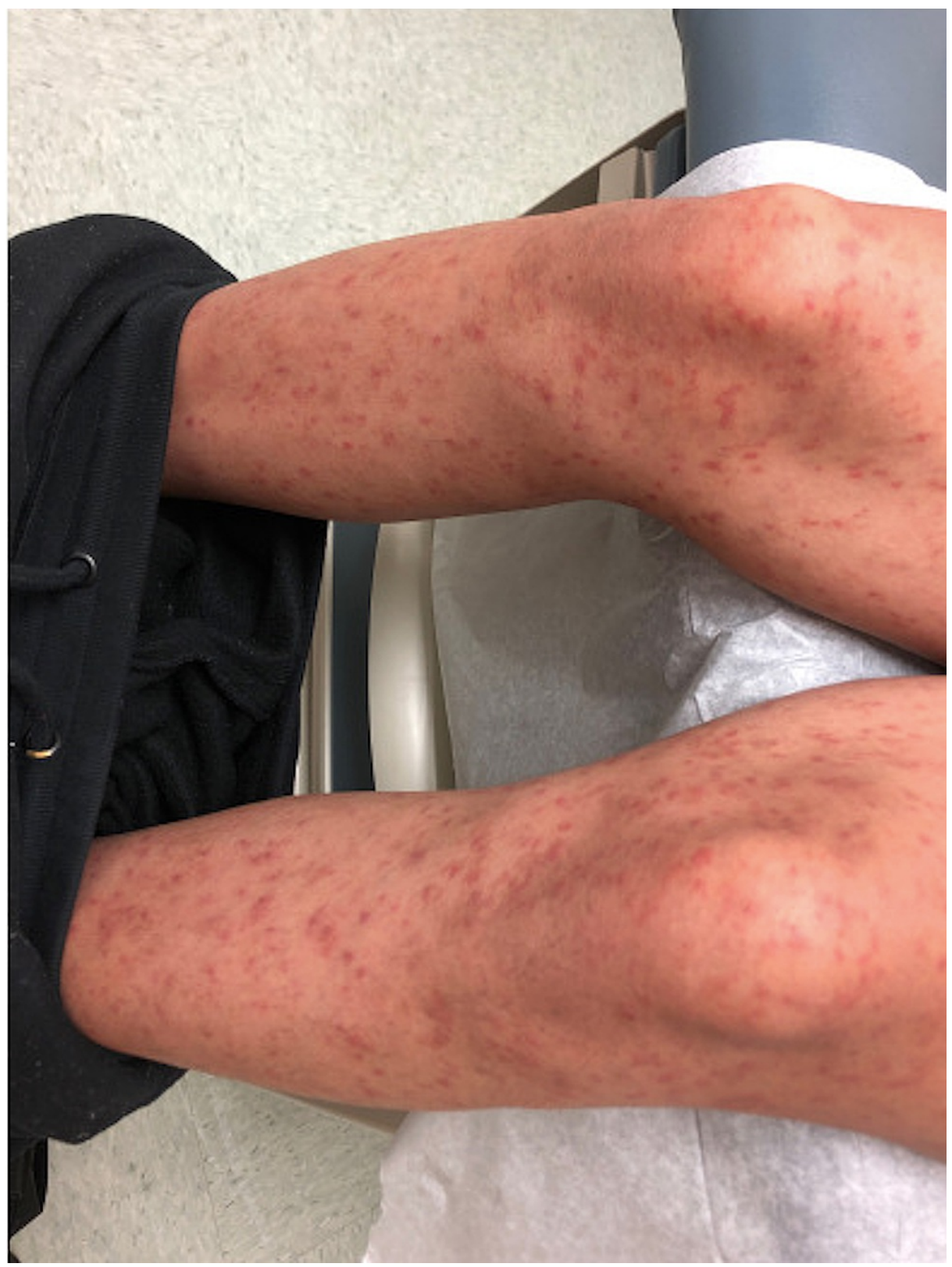

FIGURE 1: Schamberg disease.

Non-blanching erythematous and brown papules and macules on the lower extremities. 


\section{Cureus}

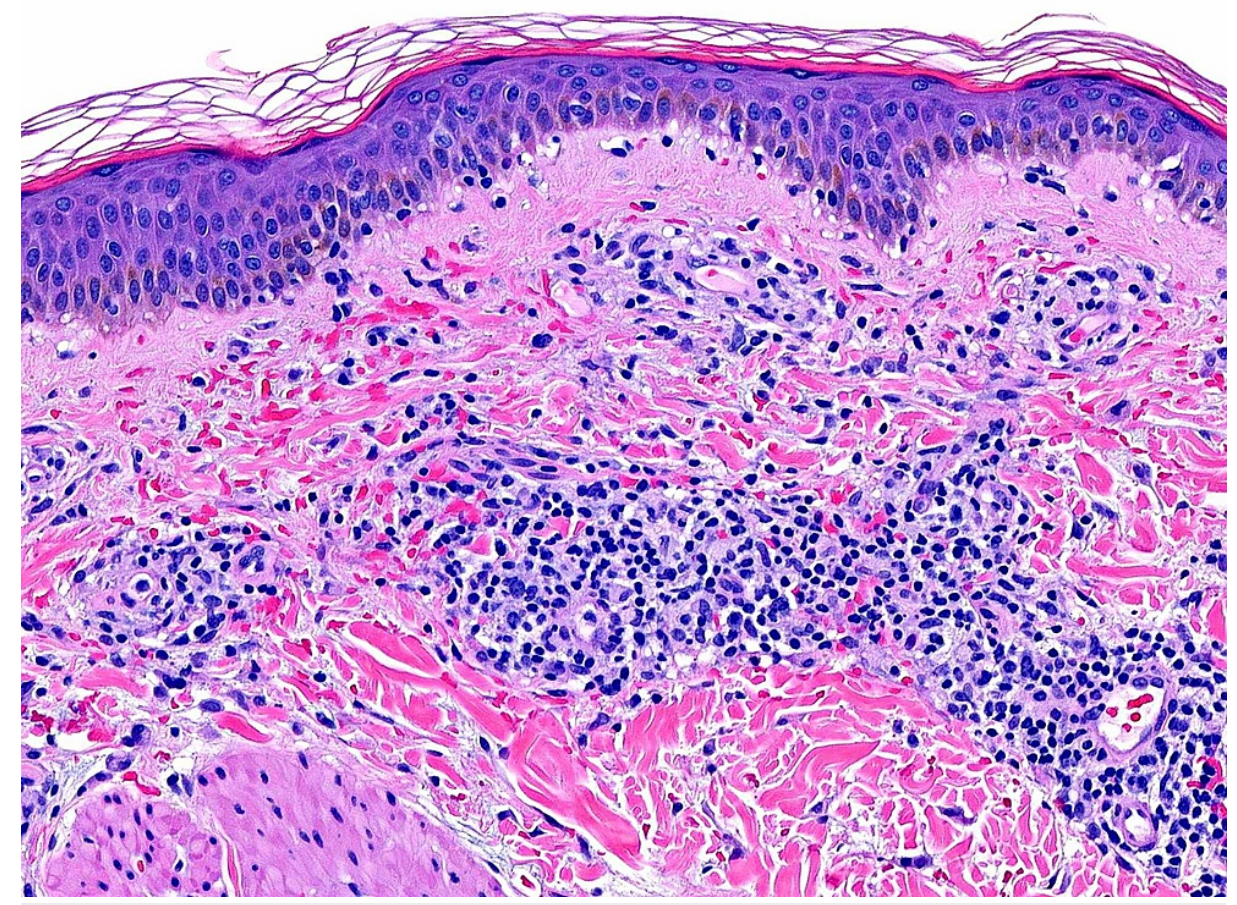

FIGURE 2: Schamberg disease histopathology.

Superficial perivascular infiltrate of lymphocytes with numerous extravasated erythrocytes, some along the dermoepidermal junction (H\&E: 200x magnification).

H\&E, hematoxylin and eosin

At the 1.5-month follow-up, the patient endorsed some improvement of her lesions with the 10-day taper of prednisone. However, her lesions quickly recurred soon after. At that time, she was initiated on oral ascorbic acid $500 \mathrm{mg}$ twice daily and oral rutoside $50 \mathrm{mg}$ twice daily. After three months of treatment, there was significant improvement in the patient's lesions with complete lesion clearance at four months (Figure 3). 


\section{Cureus}

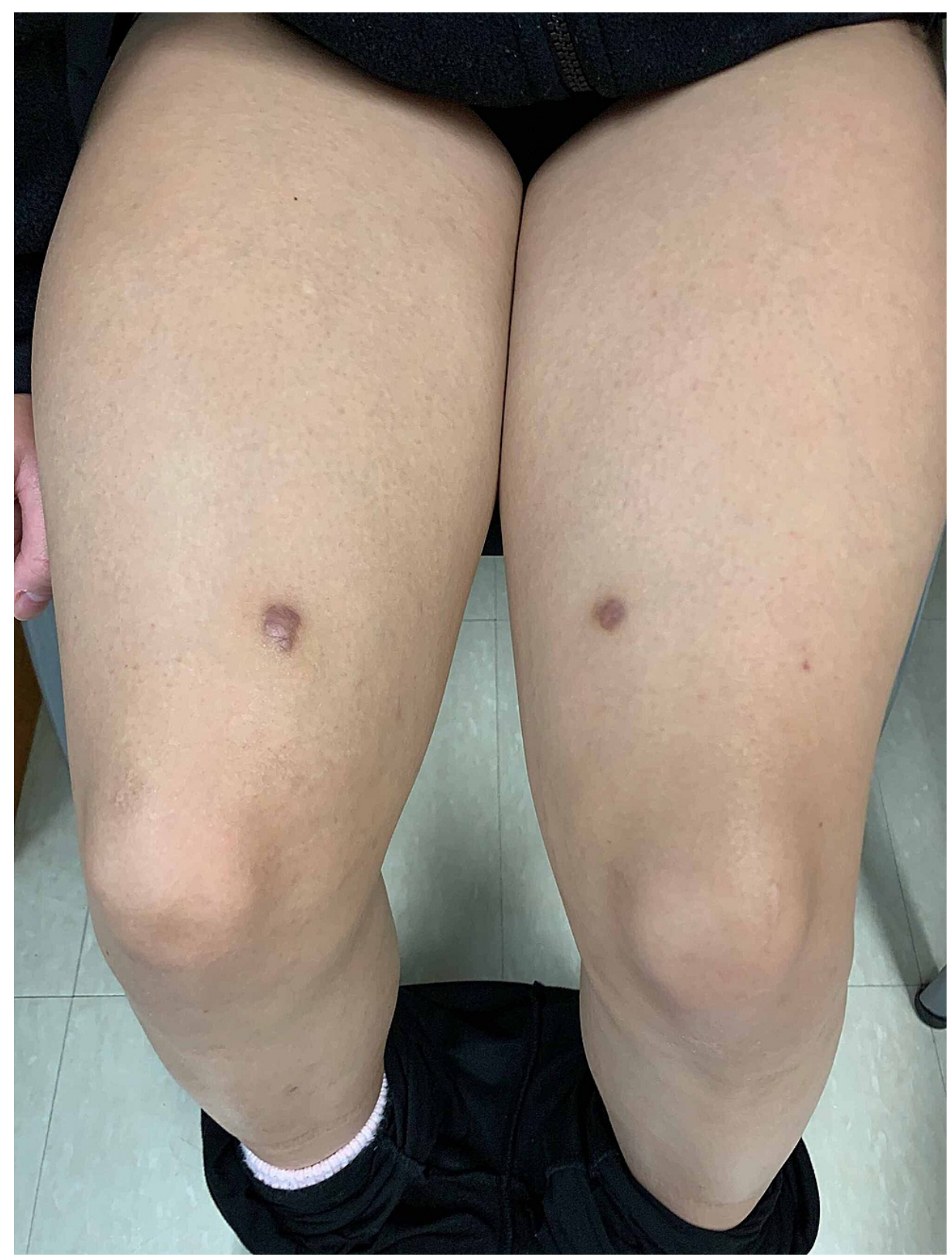

\section{FIGURE 3: Schamberg disease.}

Four months post rutoside and ascorbic acid treatment. Two hyperpigmented scars at the sites of punch biopsies.

\section{Discussion}

Few studies have tested the efficacy of rutoside and ascorbic acid in the treatment of PPD. A 1999 pilot study demonstrated that among three patients with variable duration of disease courses, full remission was achieved within four weeks of treatment, and remission was maintained at three months post-treatment [4]. Another study conducted between 2004 and 2011 found that $71.4 \%$ of its 35 participants treated with rutoside and ascorbic acid achieved full clearance of all lesions with a mean response rate of 7.9 weeks and mean treatment duration of 8.2 months [5].

The effectiveness of these treatments is related to both the hypothesized pathogenesis of PPD and the effect these agents have on cutaneous vasculature. PPD is thought to be due in part to the fragility of cutaneous blood vessels [6]. A contributing factor in the damage of vasculature is the generation of reactive oxygen species (ROS). ROS are known to damage blood vessels by inducing oxidative stress which, in turn, damages DNA and induces inflammation. ROS have been implicated in other vascular diseases such as

atherosclerosis, diabetes mellitus, and hypertension [7,8]. Antioxidants, such as ascorbic acid and rutoside (a flavonoid) have the ability to scavenge ROS $[9,10]$; this helps to protect vasculature from ROS by preventing them from inflicting damage. While this mechanism of scavenging has been shown to be effective and even 
curative in the treatment of PPD, it currently is not the standard of care. The current standard of care (e.g., topical steroids and trigger avoidance) targets symptom control rather than an overall cure.

Current standard treatment for Schamberg disease includes topical steroids for those with pruritus, avoiding or discontinuing possible triggers (e.g., acetaminophen, aspirin, alcohol ingestion), and the use of compression stockings for vessel support [3]. However, these treatments may not provide a benefit to all patients. Compression stockings are temporary and may not provide long-term benefit after removal.

\section{Conclusions}

The lack of any known severe side effects of rutoside and ascorbic acid for the treatment of PPD further supports its transition to standard of care. Studies suggest a linear correlation between time to response to treatment and disease duration. Our patient achieved significant improvement after approximately 12 weeks of treatment. Continued research, including randomized, controlled, clinical trials, would be justified to further demonstrate the efficacy of this treatment regimen. Exploration of different doses can help optimize treatment for the fastest and most effective treatment of PPD.

\section{Additional Information \\ Disclosures}

Human subjects: Consent was obtained or waived by all participants in this study. Conflicts of interest: In compliance with the ICMJE uniform disclosure form, all authors declare the following: Payment/services info: All authors have declared that no financial support was received from any organization for the submitted work. Financial relationships: All authors have declared that they have no financial relationships at present or within the previous three years with any organizations that might have an interest in the submitted work. Other relationships: All authors have declared that there are no other relationships or activities that could appear to have influenced the submitted work.

\section{References}

1. Schamberg JF: A peculiar progressive pigmentary disease of the skin . Br J Dermatol. 1901, 13:5.

2. Randall SJ, Kierland RR, Montgomery H: Pigmented purpuric eruptions. AMA Arch Derm Syphilol. 1951, 64:177-91. 10.1001/archderm.1951.01570080061009

3. Sardana K, Sarkar R, Sehgal VN: Pigmented purpuric dermatoses: an overview . Int J Dermatol. 2004, 43:4828. 10.1111/j.1365-4632.2004.02213.x

4. Reinhold U, Seiter S, Ugurel S, Tilgen W: Treatment of progressive pigmented purpura with oral bioflavonoids and ascorbic acid: an open pilot study in 3 patients. J Am Acad Dermatol. 1999, 41:207-8. 10.1016/s0190-9622(99)70050-2

5. Schober SM, Peitsch WK, Bonsmann G, et al.: Early treatment with rutoside and ascorbic acid is highly effective for progressive pigmented purpuric dermatosis. J Dtsch Dermatol Ges. 2014, 12:1112-9. 10.1111/ddg. 12520

6. Kang S, Amagai M, Bruckner AL, et al.: Pigmented purpuric dermatoses. Fitzpatrick's Dermatology. Edmonson KG, Davis KJ (ed): McGraw Hill Education, New York, USA; 2019.

7. Halliwell B: The role of oxygen radicals in human disease, with particular reference to the vascular system . Haemostasis. 1993, 23:118-26. 10.1159/000216921

8. Taniyama Y, Griendling KK: Reactive oxygen species in the vasculature: molecular and cellular mechanisms. Hypertension. 2003, 42:1075-81. 10.1161/01.HYP.0000100443.09293.4F

9. Robak J, Gryglewski RJ: Flavonoids are scavengers of superoxide anions. Biochem Pharmacol. 1988, 37:83741. 10.1016/0006-2952(88)90169-4

10. Frei B: Reactive oxygen species and antioxidant vitamins: mechanisms of action . Am J Med. 1994, 97:5-13. 10.1016/0002-9343(94)90292-5 